\title{
EFFECTS OF BARIATRIC SURGERY ON THE METABOLIC SYNDROME
}

\author{
Efeitos da cirurgia bariátrica sobre a síndrome metabólica
}

\author{
Jimmy Ali Saadallah AYOUB, Paulino Alberto ALONSO, Ligia Maria Vaz GUIMARÃES
}

From Hospitalar Complex Edmundo Vasconcelos, Department of Gastrosurgery, São Paulo, SP, Brazil.

HEADINGS - Obesity. Metabolic syndrome. Diabetes mellitus. Bariatric surgery.
ABSTRACT-Background - Morbid obesity is a state of insulin resistance associated with excess of visceral fat, which is involved in the development of metabolic syndrome. In obesity, conservative therapies promote improvement of the metabolic syndrome, but weight regain is common. The Roux-en-Y gastric bypass results in weight loss, more significant and sustained, besides promoting improvement of the metabolic syndrome, that is a risk factor for development of systemic atherosclerotic disease. Aim - To demonstrate that bariatric surgery promotes the reversal of the metabolic syndrome. Methods - The study included 74 obese patients underwent to Rouxen-Y gastric bypass by laparoscopy. Were evaluated with weight measurement, waist circumference, body mass index, blood pressure and blood glucose levels, triglycerides, total cholesterol and HDL fraction, preoperative and over six months after operation. To compare means it was used the non-parametric Friedman test and the Wilcoxon test, level of significance $p<0.05$. Results - There were 52 women and 22 men with mean age of 34.6 years. The range of follow-up was six months. The average body mass index preoperatively was 42 and six months after operation was 29.6. It was confirmed a statistically significant difference between the moments in all the quantitative variables analyzed. Conclusion - It can be inferred that bariatric surgery is an effective method of weight loss and normalization of parameters used in the diagnosis of metabolic syndrome.

\section{Correspondence:}

Jimmy Ali Saadallah Ayoub,

e-mail: dr.jimmyayoub@gmail.com

Source of funding: none

Conflict of interest: none

Received: 17/12/2010

Accepted for publication: 25/01/2011

DESCRITORES - Obesidade. Síndrome metabólica. Diabetes mellitus. Cirurgia bariátrica.
RESUMO - Racional - A obesidade mórbida é um estado de resistência à insulina associado ao excesso de gordura visceral, condições que contribuem para o desenvolvimento da síndrome metabólica. Na obesidade, os tratamentos conservadores promovem melhora da síndrome metabólica, mas a recuperação de peso é frequente. A derivação gástrica em $Y$-de-Roux resulta em perda de peso, mais significativa e sustentada, além de promover melhora da síndrome metabólica, que é condição de risco para o desenvolvimento de doença aterosclerótica sistêmica. Objetivo - Demonstrar que a cirurgia bariátrica promove a reversão da síndrome metabólica. Métodos - O estudo foi realizado com 74 pacientes obesos, submetidos a derivação gástrica em Y-de-Roux por videolaparoscopia. Foram avaliados por meio de dados antropométricos e laboratoriais, com a aferição do peso, circunferência abdominal, índice de massa corporal, pressão arterial sistêmica e a dosagem de glicemia, triglicérides, colesterol total e sua fração HDL, no pré-operatório e ao longo de seis meses após a operação. Para comparação de médias foi utilizado o teste não paramétrico de Friedman e, quando necessário, o teste de Wilcoxon, considerando nível de significância valor de $\mathrm{p}<0,05$. Resultados - Houve 52 mulheres e 22 homens, com a média de idade de 34,6 anos. O intervalo de seguimento foi de seis meses. A média do índice de massa corporal no pré-operatório era de 42 e após seis meses foi de 29,6. Demonstrou-se diferença estatisticamente significativa entre os momentos, quanto a todas as variáveis quantitativas analisadas. Conclusão - Pôde-se inferir que a cirurgia bariátrica é meio eficaz de perda de peso e normalização precoce das alterações antropométricas e laboratoriais utilizadas no diagnóstico da síndrome metabólica. 
INTRODUCTION

Tn recent years, morbid obesity has emerged as a serious threat to public health ${ }^{8}$. The World Health Organization acknowledged the existence of an epidemic obesity in most developed and developing countries ${ }^{12}$. Obesity is associated with multiple comorbidities, which result in increased morbidity and mortality, as prime example of the metabolic syndrome (MS).

It is modern disease, as a result of inappropriate diet and sedentary lifestyle. The increased morbidity is mediated primarily by insulin resistance, diabetes, hypertension and dyslipidemia. Morbid obesity is a state of insulin resistance, where there is always excess visceral fat. The presence of insulin resistance and visceral adiposity contributes to the prevalence of MS in almost all patients with morbid obesity ${ }^{2}$. It is a condition of risk for the development of systemic atherosclerotic disease, especially coronary heart disease, and is related to the development of type 2 diabetes ${ }^{11}$.

The treatment of MS can be directed to its various manifestations, using specific pharmacological approaches for each of its components. Another treatment option is focused on the pathophysiology, ie in adiposity and insulin resistance. Conservative treatments, non-drug therapies such as diet therapy and exercise, reduce visceral obesity and insulin resistance, with many benefits on the clinical manifestations of $\mathrm{MS}^{6}$. Similarly, the pharmacological treatment of insulin resistance with drugs sensitizing action of insulin, positively affects various manifestations of MS.

In morbid obese patients, conservative treatments have proven effective in promoting improvement of MS, however, there is no maintenance of weight loss in almost all individuals ${ }^{10}$. Bariatric surgery has proved effective in causing significant loss and sustained weight loss in morbidly obese patients.

This study aims to demonstrate the progressive improvement of the components of metabolic syndrome associated with morbid obesity, through the comparison of anthropometric data and laboratory over six months after the completion of Roux-en-Y gastric bypass.

\section{METHODS}

Longitudinal, prospective, interventional study, whose inclusion criteria were patients with morbid obesity with metabolic syndrome. Was performed by a team of bariatric surgery of the Hospital Complex Edmundo Vasconcelos, São Paulo, Brazil. Patients were informed about the research objectives and subsequently signed a consent form in accordance with the approval by the Ethics in Research of the hospital, under the number 0027.0.256.000-10.

All patients were followed priory in the hospital for a period exceeding 24 months, with failed attempts in clinical treatment. For surgical approach was used to Resolution No. 196/GM of February 29, 2000, from the Ministry of Health, which defined according to consensus established by the Brazilian Society for Bariatric Surgery/SBCB the clinical indications for performing bariatric surgery (major obese patients), lasting more than two years, with Body Mass Index - BMI above $40 \mathrm{~kg} / \mathrm{m}^{2}$ and resistant to conservative treatments (diet, psychotherapy, medication, exercise) performed continuously for at least two years and obese patients with BMI above $35 \mathrm{~kg} / \mathrm{m}^{2}$, patients with chronic disease (diabetes, hypertension, arthropathy, herniated disc, sleep apnea) whose clinical situation is aggravated by obesity. Patients who fit the criteria above, had confirmed the appointment of bariatric surgery, should also present no specific endocrine diseases, absence of mental disorders (alcoholism, drug addiction and others), lack of physical/clinical contraindication to large operations (cirrhosis, heart disease, lung disease, chronic renal failure and others).

All patients underwent the same preoperative evaluation. Were done plasma levels of total cholesterol, $\mathrm{HDL}$, triglycerides and blood glucose. Was also measure, for comparison, anthropometric data: height, weight, body mass index (BMI), waist circumference and blood pressure, a month before the operation, considered time zero (TO) of the study.

The minimum age for inclusion was 18 years and maximum 60. Morbidly obese patients included were those who had criteria to be included on the diagnosis of MS. They needed to have two or more of the following criteria: increased waist circumference in men> $101 \mathrm{~cm}$ and that in women> $87 \mathrm{~cm}$; TGL high, $>150 \mathrm{mg} / \mathrm{dL}, \mathrm{HDL}$ cholesterol decreased, in man <than $40 \mathrm{mg} / \mathrm{dL}$ in women and $<50 \mathrm{mg} / \mathrm{dL}$, high blood pressure $>130 / 85 \mathrm{mmHg}$ and elevated fasting glucose $>100 \mathrm{mg} / \mathrm{dL}$.

All studied patients underwent gastric bypass in Roux-en-Y. Was used the technique FobiCapella, with the construction of a gastric pouch using a calibrated probe Fouchet $12 \mathrm{~mm}$; then a gastroenterostomy (alimentary) was done with 100 $\mathrm{cm}$ and finally one enterobiliary also of $100 \mathrm{~cm}$, using laparoscopic linear staplers. Upon completion of all operations was tested with methylene blue, to detect possible perforations.

The outpatient follow-up occurred with the first visit seven days after the date of discharge, and then monthly. The laboratory tests (fasting glucose, total cholesterol and HDL, triglycerides), measurement of 
anthropometric data (weight, height, BMI and waist circumference) and blood pressure were established for the preoperative, 1,3 and 6 months after the operation, in order to compare the four moments of time in all variables.

Results were presented considering mean and standard deviation. Friedman and Wilcoxon non parametricum test was used with significance level of $p$ $<0.05$.

\section{RESULTS}

Were evaluated 74 obese patients with MS, who underwent surgical treatment from February 1, 2010 to July 30, 2010. There were more females $70.3 \%$ (52). The mean age was 34.74 years, the minimum 20 years and maximum 58 years.

The procedure was performed by the same surgical team and the laparoscopic approach was possible in all cases. There was no case of conversion to open technique, and the average operation time of two hours. Patients were on average three days in hospital. No complications occurred postoperatively. Tables and figures of quantitative variables are presented. In all moments of evaluation there was statistical difference between the studied periods.

Table 1 shows that there was a gradual reduction of weight values over time, since the average initial (T0) was 115.5 pounds and at six months after the operation (T6) it reached 80.7 pounds.

TABLE 1 - Comparison of moments of time for weight

\begin{tabular}{|c|c|c|c|c|}
\hline Weight & T0 & T1 & T3 & T6 \\
\hline Average & 115,5 & 103,5 & 92,3 & 80,7 \\
\hline Median & 112,4 & 102,5 & 90,0 & 79,6 \\
\hline Standard deviation & 20,5 & 18,7 & 17,4 & 15,8 \\
\hline Q1 & 102,3 & 92,2 & 81,0 & 70,8 \\
\hline Q3 & 127,3 & 114,0 & 101,5 & 87,1 \\
\hline N & 74 & 69 & 65 & 56 \\
\hline IC & 4,7 & 4,4 & 4,2 & 4,1 \\
\hline p-value & \multicolumn{3}{|c}{$<0,001$} \\
\end{tabular}

There was a reduction of BMI values over time, since the initial average (T0) was 42 and (T6) reached 29.6, confirming the statistical difference between the moments in BMI (Table 2).

TABLE 2 - Comparison of moments of time for BMI

\begin{tabular}{|c|c|c|c|c|}
\hline BMI & T0 & T1 & T3 & T6 \\
\hline Average & 42,0 & 37,7 & 33,6 & 29,6 \\
\hline Median & 41,3 & 37,1 & 32,7 & 28,7 \\
\hline Standard deviation & 4,6 & 4,7 & 4,7 & 4,1 \\
\hline Q1 & 38,6 & 34,6 & 30,3 & 26,4 \\
\hline Q3 & 44,4 & 40,5 & 36,3 & 32,5 \\
\hline N & 73 & 69 & 65 & 56 \\
\hline IC & 1,1 & 1,1 & 1,1 & 1,1 \\
\hline p-value & & \multicolumn{2}{c}{$<0,001$} & \\
\end{tabular}

Blood glucose averages, as well as the triglycerides, at $\mathrm{T} 1$ were below the value considered diagnostic criteria of MS.

Was used the Friedman test to compare the times for the variables HDL and waist circumference, separately by sex. There was a significant difference between times for waist circumference, both men and women, showing a gradual decrease it over time. The mean waist circumference for men in T6 $(99.1 \mathrm{~cm})$ was considered normal in the diagnostic criteria for MS, showing a significant fall months after the operation. However, regarding the variable $\mathrm{HDL}$, it was concluded that the operation did not promote its elevation over time; so, this criterion for diagnosis of MS does not change with bariatric surgery.

Finally, was categorized the value of BMI according to WHO classification. Was compared the times for the distribution of relative frequency (percentage), where was used the test of equality of two proportions. The comparison of percentages between the periods was performed on each level of response. As an example, was analyzed the degree of obesity IIl, where T0 has $63.0 \%$ of patients at T6 and this percentage reached $1.8 \%$, and this reduction was considered statistically significant.

\section{DISCUSSION}

Since the National Health defined the criteria for application of bariatric surgery rates of morbidity and mortality associated with surgery, felt considerably due to the use of laparoscopy, development of perioperative care and a better understanding of obesity ${ }^{7,9}$.

The various types of operation have different results with $68.2 \%$ loss for the bypass of the duodenum, which was used in this study (Fobi-Capella).

Today, bariatric surgery is a potent weapon in the treatment of morbid obesity and comorbidities that surround this disease. It is known that the duodenal and jejunal bypass done in bariatric surgery, gradually reduces the fasting blood glucose and improves insulin resistance. Currently, bariatric surgery has also become known as metabolic surgery, the evidence suggests that several studies have shown in relation to effective treatment of diabetes mellitus and cure of MS. The reduction of the caloric-lipidic intake improves insulin sensitivity and lipid malabsorption in 40\%; this are the main mechanisms for improving lipid reduction ${ }^{1}$. Decrease of hyperinsulinemia and insulin resistance, reduction of sympathetic hyperactivation as a result of reduced levels of leptin and reduced intraabdominal hypertension, chronic feature of obesity, are the main mechanisms related to the reduction or improvement in blood pressure ${ }^{5}$. The cure of MS after 
the operation was described as possible, secondary to improvement of insulin sensitivity ${ }^{11}$. The gastric bypass have been associated with prevention of 99 to $100 \%$ of cases of glucose intolerance to diabetes, in the medium-term follow-up ${ }^{3}$.

The reversal of MS and its manifestations should lead to increase life expectancy, since the majority of deaths are related to cardiovascular events, being SM is a risk condition for macrovascular disease. Therefore the reduction in mortality with the operation is partly mediated by the reversal of MS in operated patients ${ }^{4}$. Thus, MS can be considered a surgical condition associated with obesity.

\section{CONCLUSION}

Bariatric surgery is an effective way of losing weight, and duodenal-jejunal bypass done can directly control the SM. Considering the current diagnostic criteria, there is reversal or cure of SM in almost all patients after bariatric surgery.

\section{REFERENCES}

1. Buffington CK, Cowan GS Jr, Smith H. Significant changes in the lipid-lipoprotein status of premenopausal morbidly obese females following gastric bypass surgery. Obes Surg 1994;4:328-35.
2. Deitel M. Overweight and obesity worldwide now estimated to involve 1.7 billion people. Obes Surg 2003;13:329-30.

3. Ferchak CV, Meneghini LF. Obesity, bariatric surgery and type 2 diabetes - a systematic review. Diabetes Metab Res Rev 2004;20:438-45.

4. Geloneze B, Geloneze SR, Picolo M, Repetto EM, Murro AL, Tambascia MA. Metabolic syndrome as a surgical condition. Obes Surg 2002;12:459.

5. Geloneze B, Tambascia MA, Pareja JC, Repetto EM, Magna LA, Pereira SG. Serum leptin levels after bariatric surgery across a range of glucose tolerance from normal to diabetes. Obes Surg 2001;11:693-8.

6. Grundy SM, Hansen B, Smith SC Jr, Cleeman JI, Kahn RA; American Heart Association; National Heart, Lung, and Blood Institute; American Diabetes Association. Clinical management of metabolic syndrome: report of the American Heart Association/National Heart, Lung, and Blood Institute/American Diabetes Association conference on scientific issues related to management. Arterioscler Thromb Vasc Biol 2004;24:e19-24.

7. Maggard MA, Shugarman LR, Suttorp M. Meta-analysis: surgical treatment of obesity 2005;142:547-59.

8. Mokdad AH, Marks JS, Stroup DF, et al. Actual causes of death in the United States, 2000. JAMA. 2004;291:1238-1264.

9. Nguyen NT, Wilson SE, Wolfe BM. Rationale for laparoscopic gastric bypass. J AM Coll Surg 2005;200:621-9.

10. Pi-Sunyer FX. The obesity epidemic: pathophysiology and consequences of obesity. Obes Res 2002;10(suppl. 2):97S-104S.

11. Reaven GM. Banting lecture. Role of insulin resistance in human disease. Diabetes 1988;37:1595-607.

12. World Health Organization. Obesity: preventing and managing the global epidemic. Report of a WHO consultation. World Health Organ Tech Rep Ser. 2000;894:1-253. 